\title{
Update on severe asthma: what we know and what we need
}

\section{Gaga*, E. Zervas* and P. Chanez ${ }^{\#}$}

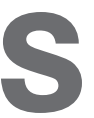
evere asthma patients experience frequent or debilitating symptoms and limitations in their activities, have frequent exacerbations and hospitalisations and account for over half of the cost of the disease and most of its mortality [1, 2]. Because the disease is chronic, debilitating and may prove fatal, it is imperative to understand the mechanisms and factors associated with it and to treat it effectively. This update on severe asthma presents information regarding epidemiology, clinical assessment, risk factors, pathophysiology and management of severe asthma and includes recent relevant publications.

\section{DEFINITION}

According to the Global Initiative for Asthma (GINA) definition, patients who experience daily symptoms, frequent exacerbations, frequent nocturnal asthma symptoms, limitation of physical activities, forced expiratory volume in $1 \mathrm{~s}$ (FEV1) or peak expiratory flow (PEF) $60 \%$ predicted and PEF or FEV1 variability $>30 \%$ before initiation of treatment should be classified as having severe persistent asthma [1, 2]. Once treatment is initiated, the response to treatment is also important and is measured by the level of control. This dual assessment creates some confusion as the terminology is not standardised and the terms are often used interchangeably [3]. However, both concepts of asthma severity and control are important in the evaluation of patients and their response to treatment: some patients respond to treatment and become asymptomatic while others remain uncontrolled. Therefore, the diagnosis of "severe asthma" or "severe refractory asthma" is based on both the clinical features of the disease and the daily medication regimen that the patient is receiving. Patients who need oral corticosteroids or very high dose inhaled steroids to remain under control as well as patients with ongoing asthma symptoms, despite being on the appropriate maintenance therapy (high dose inhaled corticosteroids (ICS) combined with long-acting $\beta_{2}$-agonists (LABA)), should be regarded as having severe asthma [1, 3-5]. Although the definition includes the response to treatment, it must be taken into account that response to treatment may be slow or, conversely, a patient may seem to respond but may relapse quickly and present with new exacerbations. Therefore, a relatively long period of monitoring and treatment is necessary before labelling any patient as having severe/refractory asthma. In addition, during this period, other possible diagnoses should be investigated and excluded [6]. The latest definition was given 2 yrs ago and is as follows: severe asthma is diagnosed in patients with refractory asthma that remain difficult to control despite a thorough re-evaluation of the diagnosis and after $>6$ months of close follow-up by a physician specialising in asthma [7].

Many factors have been associated with disease severity, loss of control and exacerbations. These include viruses, environmental and occupational sensitisers, comorbidities, ethnicity, sex and increased body mass index (BMI). Some factors cannot be altered but others must be avoided or treated. Therefore, the term severe refractory asthma should apply to patients who remain difficult to control despite an extensive reevaluation of diagnosis, avoidance or treatment of exacerbating factors and following a period of $\geqslant 6$ months of close follow-up and tailored and rigorous management by an asthma specialist.

\section{PATHOPHYSIOLOGY \\ Bronchial inflammation}

Inflammation is an important feature in severe asthma [8]. Inflammatory phenotypes of severe asthma can be characterised by persistence of eosinophilic or neutrophilic infiltration, while in some cases, no inflammatory infiltration is noted (paucigranulocytic) [9]. Usually, inflammatory cells are present and activated in the airways of severe asthmatics and persist despite treatment, but their relevance to control and severity of the disease is largely unknown. These cells include not only eosinophils and neutrophils but $\mathrm{T}$ lymphocytes, mast cells and macrophages while structural cells are also involved in the inflammatory reaction and remodelling in asthma.

\section{Inflammatory cell infiltration}

Regarding the eosinophilic phenotype, there are data suggesting that there is a relationship

\section{AFFILIATIONS}

*7th Respiratory Medicine Dept and Asthma Centre, Athens Chest Hospital, Athens, Greece.

\#Dept of Respiratory IIIness, Universite de la Mediteranee Marseille, France.

\section{CORRESPONDENCE}

M. Gaga

7th Respiratory Medicine Dept Athens University

Sotiria Hospital

152 Mesogion Ave Athens 11527

Greece

E-mail: minagaga@yahoo.com

Received:

March 032009

Accepted:

March 032009

\section{STATEMENT OF INTEREST}

M. Gaga has received educational grants from GlaxoSmithKline,

research and consultancy fees from

AstraZeneca, Novartis, Nycomed, Boehringer Ingelheim and UCB. E. Zervas has received an educational grant from GlaxoSmithKline, has received fees as a speaker from AstraZeneca, Novartis and Nycomed and has received research funding from Boehringer Ingelheim, GlaxoSmithKline and Schering Plough. P. Chanez has consultancy and/or speaking arrangements with Novartis, AstraZeneca, Boehringer Ingelheim, Teva, Actelion, Chiesi and GlaxoSmithKline. P. Chanez sits on the advisory board for Centocor, and receives grant money and/or research from Schering Plough.

PROVENANCE

Submitted article, peer reviewed.

European Respiratory Review

Print ISSN 0905-9180

Online ISSN 1600-0617 
between the perception of symptoms and eosinophilic inflammation but these data refer to asthma in general and there is no specific study on severe asthma [10]. It seems that sputum analysis discriminates eosinophilic inflammation in severe asthma better than cell differential analysis of endobronchial biopsies [11]. The factors controlling eosinophilic inflammation in severe asthma are not clear. While interleukin (IL)-5, eotaxin and other mediators may promote the eosinophilic infiltrates, there is no upregulation of these specific chemoattractants in severe eosinophilic asthma as opposed to the milder forms of the disease [12]. However, eosinophilic inflammation is impacting on structural changes of the airways [13].

Severe asthma may also be associated with neutrophilic inflammation $[5,14]$ but the precise role of neutrophils remains to be determined. Neutrophilia may represent a continuous influx of cells from the bloodstream due to continuous antigenic stimulation of the bronchi or it may be influenced by the high levels of steroid treatment [15]. Several mediators linked to neutrophils (leukotriene (LT)B $\mathrm{B}_{4}$, IL-8, macrophage inflammatory protein- $1 \alpha$ and tumour necrosis factor (TNF)- $\alpha$ ) have been shown to be increased in severe asthma [14, 16]. They induce neutrophil chemotaxis, activation and survival and upregulate endothelial adhesion molecules. Epidermal growth factor receptor (EGFR), a marker of epithelial stress / damage, is increased in proportion to disease severity. EGFR expression in the bronchial epithelium correlates with IL-8 indicating that EGFR can also contribute to this sustained neutrophilic inflammation [17, 18].

The mild form of asthma and most of the "old" animal models of asthma are characterised by involvement of T-helper (Th)2 mediated inflammation. Th2 cells orchestrate the recruitment of a range of inflammatory cells and enhance mediator release [19]. However, the Th2 immune process by itself is often inadequate to explain the persistence of inflammation in severe asthma. In addition to Th2 cytokines or chemokines, upregulation of both innate and Th1 pathway elements in severe asthma has been observed. Although at baseline T-cell activation is Th2-biased and there is a T regulatory (Treg) deficiency, a mixed Th1/Th2 activation and an increase in Tregs occurs during exacerbations. Furthermore, cytokines considered to be involved in Th1 immunity may play a dual Th1/Th2 role in asthma, as has been shown for osteopontin [20].

The persistence of inflammation in severe asthma may also result from deficiencies in endogenous homeostatic processes that promote resolution of inflammation. Of interest, a lower biosynthetic capacity for lipoxins, which are endogenously derived protective signals, is linked to severe asthma [21, 22]. The studies from the Severe Asthma Research ProgramNational Institute of Health cohort confirm that there is lipoxin underproduction and greater oxidant stress in severe asthma [23, 24]. In addition, alveolar macrophages from severe asthmatic individuals have decreased production of other potentially protective mediators (i.e. prostaglandin (PG)E2 and 15-HETE (15-hydroxyeicosatetraenoic acid)) and defective apoptotic inflammatory cell uptake [25].

\section{Structural cell abnormalities}

Epithelial cell and smooth muscle abnormalities and goblet cell hyperplasia are observed in the majority of fatal and/or severe asthmatics and probably contribute to airway narrowing. There has been increasing interest in the mechanisms involved in differentiation and repair of the airway epithelium, especially as it applies to severe asthma. Markers of apoptosis, such as Bcl-2, are high in asthmatics while markers of proliferation and activation, such as proliferating cell nuclear antigens, nuclear factor- $\kappa \mathrm{B}$ and CD40-L, show increased expression in corticosteroid-dependent asthma [26]. Profibrotic cytokines, such as transforming growth factor- $\beta$, produced by the epithelium and submucosal cells are specifically increased in the eosinophilic phenotype of severe asthma [27]. Increased airway smooth muscle is found in the bronchi of individuals who died of status asthmaticus and in endobronchial biopsies from living severe asthmatics. In addition to increasing closure of the airways hyperreactive smooth muscle contraction, smooth muscle cells can also contribute to the recruitment of inflammatory cells into the bronchi producing pro-inflammatory cytokines and chemokines and expression of leukocyte adhesion molecules [28]. Neurogenic mechanisms contribute to inflammation in asthma [29] but this role in severe asthma needs to be further explored.

Airway wall thickening is observed in many severe asthmatics and emerging evidence suggests that parenchymal abnormalities may also influence airflow limitation in severe disease [30]. Previous autopsy and lung resection studies have shown the small airways to be inflamed and thickened in asthma [31, 32]; however, the functional consequences of these structural changes have been difficult to ascertain.

Adequate tissue sampling of the distal lung for the evaluation of the outer airway wall, small airways and their surrounding parenchyma is still needed for mechanistic insights. In addition, static and dynamic imaging studies, performed in well phenotyped, genotyped and physiologically characterised severe asthmatics are required to better link structure to function and genetic suceptibility. A recent study has shown that quantitative computed tomography determined air trapping in asthmatic subjects and identified a group of individuals at high risk for severe disease, which includes patients with a history of pneumonia, neutrophilic inflammation or atopy [33].

\section{Poor corticosteroid response}

Complete absence of response to corticosteroid in severe asthma is very rare. Much more common is a reduced responsiveness, often described as corticosteroid-dependent asthma or refractory asthma, where large doses of inhaled corticosteroids (ICS) and sometimes oral/systemic corticosteroids are needed to control asthma [34, 35]. Poor responsiveness to corticosteroid is likely to be multifactorial; it depends on phenotype and environmental exposure and changes over time. As different forms of glucocorticoid receptors have recently been described, examination of potential genetic determinants for CS responsiveness is also recommended [36]. Macrophages may be involved in steroid resistance through activation and induction of lipopolysaccharide signalling pathways [37]. Moreover, alveolar macrophages from patients with severe asthma demonstrate corticosteroid insensitivity associated with increased p38 mitogen activated protein kinase activation [38]. 


\section{EPIDEMIOLOGY AND RISK FACTORS}

It is estimated that $5-10 \%$ of asthmatics suffer from severe asthma. However, there is a scarcity of epidemiological studies assessing severity and an urgent need for more studies to define the true prevalence of severe refractory asthma. High healthcare costs are associated with severe asthma. GODARD et al. [39] showed that direct costs for goods and services, numbers of consultations, supplementary examinations and medications, as well as indirect costs (days lost from work and adverse quality of life (QoL) parameters), all increase significantly with increasing severity. More recently, data from the North American cohort of severe asthma enrolled in The Epidemiology and Natural History of Asthma: Outcomes and Treatment Regimens (TENOR) study were analysed. The investigators examined the cost of severe controlled and severe uncontrolled asthma and reported that controlled patients experienced fewer work or school absences and less healthcare resource use than uncontrolled patients at all study time-points [8]. Using the multilevel Asthma Therapy Assessment Questionnaire (ATAQ) control score, asthma costs increased directly with the number of asthma control problems. Costs for uncontrolled patients were more than double those of controlled patients throughout the study (US\$14,212 versus US $\$ 6,452$, adjusted to the 2002 US $\$$ rate; $\mathrm{p}<0.0001)$. This study demonstrated that the economic consequence of uncontrolled disease is substantial [40].

Epidemiological studies have also examined the relationship between possible risk factors and asthma severity. The ENFUMOSA study showed that female sex, obesity and the lack of atopy were associated with more severe disease, while no childhood risk factors were identified [5, 41]. The Leiden group showed that comorbid conditions associated with frequent exacerbations are psychological disorders, sinus disease, gastro-oesophageal reflux, Chlamydia pneumonia infection, sleep apnoea and thyroid disease [42]. More recently data from the TENOR study were analysed. Factors associated with increased risk of exacerbation and hospital admissions were younger age, female sex, non-white race, BMI $>35 \mathrm{~kg} \cdot \mathrm{m}^{-2}$, post-bronchodilator FEV1 $<70 \%$ pred, history of pneumonia, diabetes, cataracts, intubation for asthma and three or more steroid bursts in the previous 3 months [43]. A final risk score ranging from $0-18$ was derived from the logistic regression model in this cohort and was highly predictive of hospitalisation or emergency department (ED) visits (table 1).

A score of 0-4 represents a low risk, scores of 5-7 represent moderate risk and a score of $\geqslant 8$ represents a high risk. Point cut-off values were based on percentages of patients with a hospitalisation or an ED visit from the original population analysis. Further analyses regarding these risk factors have been published by the TENOR group and show that increased asthma severity in black ethnicity is not explained by differences in demographics, severity or other health conditions [44]. The same investigators used the ATAQ to examine the level of control and showed that a validated questionnaire may help clinicians identify patients requiring intervention to prevent future severe asthma-related events [45]. Contrary to the ENFUMOSA data, the TENOR cohort had very high rates of skin test positivity for allergy [46] and immunoglobulin (Ig)E levels were associated with asthma severity among younger patients [47]. In children and adolescents, increased

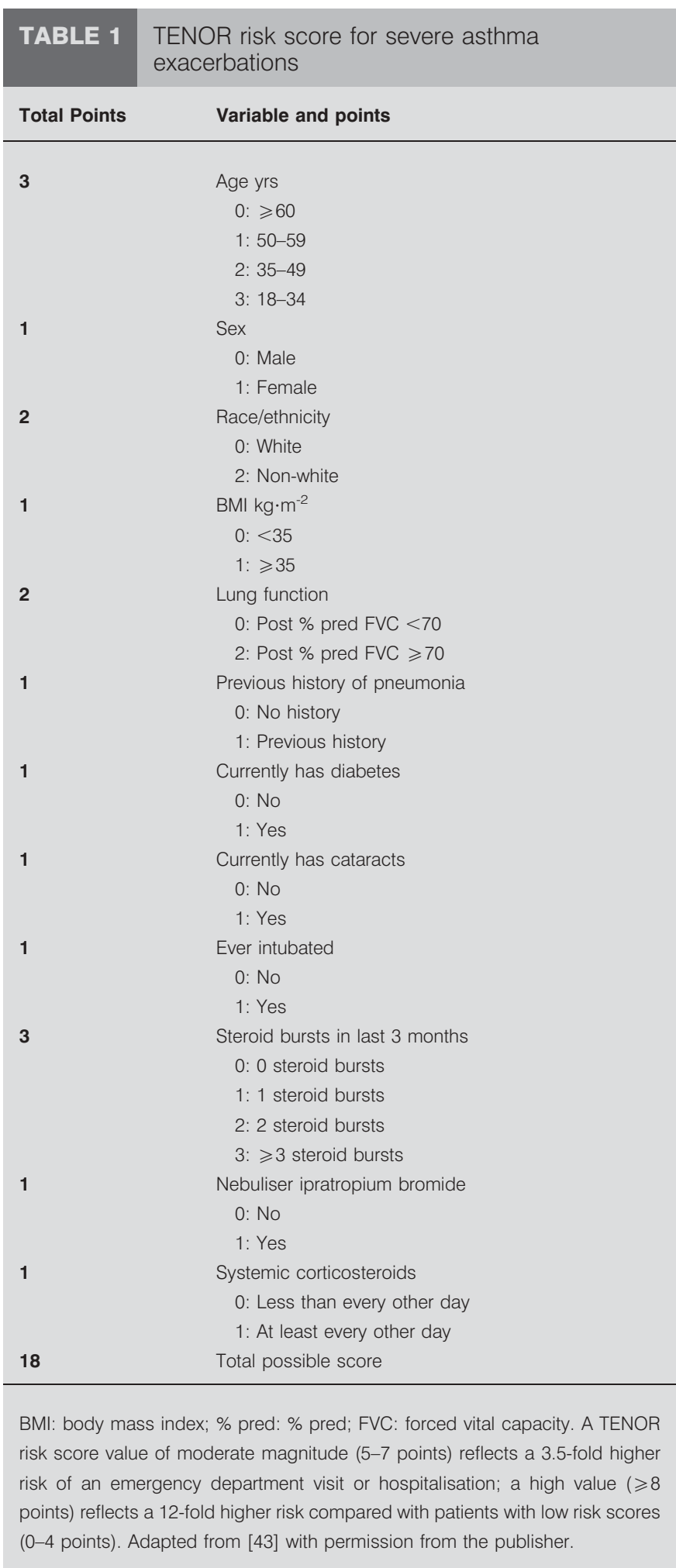

body weight was found to be associated with asthma severity in young females [48].

Risk factors associated with fixed airway obstruction have also been examined and data show that older age, male sex, black ethnicity, current or past smoking history, aspirin sensitivity and longer asthma duration are associated with persistent 
airflow limitation while protective factors were Hispanic ethnicity, higher education, family history of atopic dermatitis, pet(s) in the home and dust sensitivity $[49,50]$. Aspirin intake has also been associated with severe asthma attacks and remodelling changes $[5,50]$.

\section{CLINICAL ASSESSMENT AND RE-EVALUATION}

The assessment of both severity and control are very important. The National Asthma Education and Prevention Program guidelines base the assessment of control on two sets of parameters, those assessing impairment or disability and those assessing future risk for the patient [51]. Patients with continuous symptoms, frequent night awakenings, frequent use of reliever medications and reduced lung function are impaired in their daily activities and their QoL. Moreover, patients with frequent exacerbations, progressive loss of lung function, comorbidities and treatment-related side-effects are at increased risk of future exacerbations and poor disease outcome.

Re-evaluation should include assessment of all factors that influence asthma control and possible triggers must be adequately addressed [3, 4, 7]. Factors that can influence asthma control, such as environmental exposures, comorbid conditions, treatment adherence and, in particular, inhalation technique, must be examined meticulously. Cigarette smoking in asthma is a risk factor for poor asthma control and reduced sensitivity to corticosteroids. Every effort should be made to encourage individuals with asthma who smoke to quit [52]. Objective criteria are important in the follow-up and reevaluation of severe asthma. Therefore, during follow-up it is recommended that patients should be monitored by: validated questionnaires regarding asthma control; pulmonary function measurements; airway inflammation assessment; and QoL questionnaires [3, 4, 7]. The frequency of exacerbations and healthcare system use (including planned and unexpected/ emergency) should also be recorded. Control must be very clearly defined, as a recent study compared three different control definitions and showed that although all three definitions were correlated with future control and health economic outcomes, there were striking differences in the descriptive results across the definitions, including the proportion of patients in each category of control [53]. Differences among definitions of asthma control may lead to divergent research conclusions or treatment practices. The standardisation of control definitions remains very important.

It must be taken into account that severe asthma is a heterogeneous condition that includes several phenotypes. The types of severe asthma used to include severe occupational, brittle, pre-menstrual, steroid dependent or resistant, and aspirin induced [3,4]. These classifications are important in some aspects of management and avoidance practices but do not include information on the clinical appearance of the disease nor the inflammatory profile. At present, the aim of phenotyping is to include clinical and pathophysiological data as well as risk factors of the disease in order to specifically guide treatment. Thus phenotyping of severe asthma may be characterised by the presence of continuous symptoms [54], frequent exacerbations [42] or fixed airway obstruction [49, 55]. Furthermore, classification can be based on the presence of severe inflammation, whether eosinophilic or neutrophilic, or on the absence of inflammation but the persistence of symptoms and bronchial hyperresponsiveness [54]. Determining the phenotype in each case of severe asthma improves the current understanding of its underlying mechanisms, natural history and prognosis and helps to guide the choice of current and future treatments.

\section{TREATMENT}

High-dose inhaled steroids and LABA are the cornerstone of treatment in refractory asthma but additional medications such as theophylline, oral steroids, anti-IgE monoclonal antibody or LT-antagonists are almost always used and are recommended in the guidelines $[3,4,7]$. The choice of additional medications is based on the patient's phenotype and response [53]. However, management regimens are rarely successful in these patients and the treating physicians are often at a loss. There are still many areas of uncertainty regarding steroid responsiveness and safety issues. Increasing doses of inhaled steroids are linked with high systemic absorption and many, potentially serious, side-effects. Moreover, the dose-response curve of ICS plateaus and there are no advantages to doses equivalent to $>2,000 \mu \mathrm{g}$ beclomethasone [56]. However, individual responsiveness to steroids differs from patient to patient. Maximal dosing of ICS and bronchodilators and possible differences between ICS preparations need to be defined more clearly. Newer ICS have been introduced to the marketplace which are shown to have fewer side-effects [57]. The benefit-to-adverse effect ratio has to be examined meticulously, and careful placebocontrolled trials are needed to determine the optimal methodology of titrating CS therapy [58, 59].

The problem is that the vast majority of severe asthmatic patients remain symptomatic despite the use of combined LABA and ICS therapy. In patients at treatment steps 4 and 5 of the GINA guidelines, the use of high-dose ICS therapy and the addition of at least one LT antagonist, slow-release theophylline or even oral corticosteroids and anti-IgE in selected patients is advocated [60]. However, it seems that not all severe patients necessarily need high-dose ICS. The Leicester group showed that in patients with eosinophilic inflammation, ICS help reduce exacerbations while in symptomatic patients without evidence of inflammation ICS dosing can be reduced [54]. Furthermore, a recent study aiming to assess the response of high-dose salmeterol/fluticasone combination in a large cohort of severe or difficult-to-treat asthmatics concluded that some asthmatics achieve better outcomes while receiving a low-dose ICS/LABA combination. These findings suggest a limited value of high-dose ICS/LABA combination compared with the alternatives in this particular group of severe asthmatics [61]. Combinations of ICS and LABA have been used lately not only as maintenance but also as rescue/relief treatment. A recent Cochrane review [62] concluded that in severe asthma the use of budesonide/ formoterol for maintenance and relief demonstrated a reduction in the risk of exacerbations that require oral corticosteroids in comparison with budesonide/formoterol for maintenance and terbutaline or formoterol for relief. Furthermore, the incidence of serious adverse events in children was also less when budesonide/formoterol was used for maintenance and relief, as was demonstrated in a second study which similarly 
enrolled children who were not controlled on medium to high doses of ICS.

Anti-LTs are another add-on option to ICS/LABA for the treatment of severe asthma. As the biosynthesis of LTs is partially corticosteroid independent and increased LT levels have been reported in severe asthma [63], it is felt that anti-LTs would be beneficial in these patients. However, although guideline recommended, these drugs are added on in patients with severe asthma without definite evidence of benefit: studies have shown either improvement in a small subgroup of severe asthma patients or no improvement [64-66]. Again, specific phenotyping of asthmatic patients may help predict which patients will benefit from this treatment [67]. There is some evidence indicating that smokers [68], aspirin-intolerant [69] and, perhaps, obese asthmatics [70] may respond better. Nevertheless, prospective controlled studies using anti-LTs as add-on therapy in severe asthma need to be performed.

Anticholinergics are sometimes used as add-on treatment in severe asthma. A Cochrane review concluded that there is no evidence to support the use of anticholinergics as part of addon treatment for patients whose asthma is not well controlled using standard therapies [71]. However, recent findings have rekindled the interest regarding the use of tiotropium in severe asthma. A preliminary study by IWАмОто et al. [72] has shown an association between the responsiveness to tiotropium bromide and the type of inflammatory cells in the induced sputum of patients with severe persistent asthma. These findings indicate a rationale for using tiotropium bromide to treat severe asthma with a noneosinophilic sputum profile and this is irrespective of the patients' smoking status [72]. In another study, PARK et al. [73] found that $30 \%$ of severe asthmatics with reduced lung function respond to adjuvant tiotropium. The presence of the Arg16Gly polymorphism in $\beta_{2^{-}}$ adrenoreceptor may predict good response to tiotropium [73].

Anti-IgE treatment has been shown to help a number of patients with allergic asthma. It can be administered to patients with IgE levels 35-700 IU and a dose titrated on their IgE levels and body weight. It is administered subcutaneously once or twice a month for at least 3-6 months and is continued if the clinical outcome is favourable. In this selected group of patients, anti-IgE treatment was effective in increasing the numbers of patients who were able to reduce their inhaled steroids. It also led to a reduction in asthma exacerbations [74]. A recent study showed that discontinuation of treatment leads to recurrence of symptoms in severe asthma patients [75]. Patients responding to anti-IgE treatment also showed an improvement in symptoms of rhinitis [76].

Furthermore, there are many other classes of medication that have been, or are being currently, tested in severe asthma, for example, anti-TNF- $\alpha$ treatment has been tested in controlled studies, initially with good results [77]. However in a subsequent study, an unfavourable risk/benefit profile led to early discontinuation of study agent administration after the week-24 database lock [78]. During week 76, 20.5\% placebo and $30.3 \%$ golimumab-treated patients experienced serious adverse events, with serious infections occurring more frequently in golimumab-treated patients. One death and all eight malignancies occurred in the active groups. Therefore, it was concluded that treatment with golimumab did not demonstrate a favourable risk/benefit profile in this study population of patients with severe persistent asthma. Other steroid sparing drugs (cyclosporine, tacrolimus, methotrexate and gold) have also been used but results are unsatisfactory and side-effects are notable, thus steroids remain the cornerstone of severe asthma treatment. The addition of macrolides is beneficial in many cases and this is in step with the evidence of chronic Chlamydia infection in severe asthma $[79,80]$

Initial results of anti-IL5 (mepolizumab) were not very promising. Mepolizumab treatment did not appear to add significant clinical benefit in patients with asthma with persistent symptoms despite ICS therapy [81]. But two recent studies show that mepolizumab therapy reduces exacerbations and improves Asthma Quality of Life questionnaire score in patients with severe eosinophil asthma $[82,83]$. There are some case reports that support the use of $\operatorname{IgG}$, but there are not enough controlled studies to support this type of treatment. However, a recent study tested humanised IgG1 monoclonal antibody against the IL-2R $\alpha$-chain (CD25) of activated lymphocytes (daclizumab) and produced encouraging results [84]. Daclizumab improved pulmonary function and asthma control in patients with moderate-to-severe chronic asthma who were inadequately controlled on ICS. The mechanism of action probably involves inhibition of pro-inflammatory cytokine generation by IL-2R blockade in activated T-cells.

Bronchial thermoplasty, a bronchoscopic procedure to reduce the mass of airway smooth muscle and attenuate bronchoconstriction, has been tested in severe asthmatic patients resulting in an improvement in asthma control [85].

\section{CONCLUSION}

Over the past $20 \mathrm{yrs}$, extensive investigation of the pathogenetic mechanisms of asthma has led to a better understanding of the disease and to a more cognitive approach to its therapies. However, severe asthmatics continue to have persistent symptoms and frequent exacerbations despite specialist care and continuous, intensive, high-dose treatment. Networks of scientists have been formed and studies such as the ENFUMOSA, TENOR and BIOAIR have been carried out, helping our understanding of the disease but many questions remain unanswered. There is clearly a need to continue the global effort and collaboration for further studies and innovative treatments in severe asthma.

\section{REFERENCES}

1 Bateman ED, Hurd SS, Barnes PJ, et al. Global Strategy for Asthma Management and Prevention: GINA Executive Summary. Eur Respir J 2008; 31: 143-178.

2 Taylor DR, Bateman ED, Boulet LP, et al. A new perspective on concepts of asthma severity and control. Eur Respir J 2008; 32: 545-554.

3 Chung KF, Godard P, Adelroth E, et al. Difficult/therapyresistant asthma: the need for an integrated approach to define clinical phenotypes, evaluate risk factors, understand pathophysiology and find novel therapies. ERS Task Force on Difficult/Therapy-Resistant Asthma. European Respiratory Society. Eur Respir J 1999; 13: 1198-1208. 
4 Proceedings of the ATS workshop on refractory asthma: current understanding, recommendations, and unanswered questions. American Thoracic Society. Am J Respir Crit Care Med 2000; 162: 2341-2351.

5 The ENFUMOSA Study Group. The ENFUMOSA crosssectional European multicentre study of the clinical phenotype of chronic severe asthma. European network for understanding mechanisms of severe asthma. Eur Respir J 2003; 22: 470-477.

6 Chanez P, Godard P. Is difficult asthma still clinically meaningful? Eur Respir J 2006; 28: 897-899.

7 Chanez P, Wenzel SE, Anderson GP, et al. Severe asthma in adults: what are the important questions? J Allergy Clin Immunol 2007; 119: 1337-1348.

8 Balzar S, Wenzel SE, Chu HW. Transbronchial biopsy as a tool to evaluate small airways in asthma. Eur Respir J 2002; 20: 254-259.

9 Wenzel SE, Schwartz LB, Langmack EL, et al. Evidence that severe asthma can be divided pathologically into two inflammatory subtypes with distinct physiologic and clinical characteristics. Am J Respir Crit Care Med 1999; 160: 1001-1008.

10 Tillie-Leblond I, Montani D, Crestani B, et al. Relation between inflammation and symptoms in asthma. Allergy 2009; 64: 354-367.

11 Lemiere C, Ernst P, Olivenstein R, et al. Airway inflammation assessed by invasive and noninvasive means in severe asthma: eosinophilic and noneosinophilic phenotypes. J Allergy Clin Immunol 2006; 118: 1033-1039.

12 Shannon J, Ernst P, Yamauchi Y, et al. Differences in airway cytokine profile in severe asthma compared to moderate asthma. Chest 2008; 133: 420-426.

13 Simpson JL, Scott RJ, Boyle MJ, et al. Differential proteolytic enzyme activity in eosinophilic and neutrophilic asthma. Am J Respir Crit Care Med 2005; 172: 559-565.

14 Gibson PG, Simpson JL, Saltos N. Heterogeneity of airway inflammation in persistent asthma: evidence of neutrophilic inflammation and increased sputum interleukin-8. Chest 2001; 119: 1329-1336.

15 Gaga M. Fixed obstruction in severe asthma: not just a matter of time. Eur Respir J 2004; 24: 8-10.

16 Howarth PH, Babu KS, Arshad HS, et al. Tumour necrosis factor (TNFalpha) as a novel therapeutic target in symptomatic corticosteroid dependent asthma. Thorax 2005; 60: 1012-1018.

17 Puddicombe SM, Polosa R, Richter A, et al. Involvement of the epidermal growth factor receptor in epithelial repair in asthma. FASEB J 2000; 14: 1362-1374.

18 Hamilton LM, Torres-Lozano C, Puddicombe SM, et al. The role of the epidermal growth factor receptor in sustaining neutrophil inflammation in severe asthma. Clin Exp Allergy 2003; 33: 233-240.

19 Kay AB. Allergy and allergic diseases. first of two parts. $N$ Engl J Med 2001; 344: 30-37.

20 Xanthou G, Alissafi T, Semitekolou M, et al. Osteopontin has a crucial role in allergic airway disease through regulation of dendritic cell subsets. Nat Med 2007; 13: 570-578.

21 Levy BD, Bonnans C, Silverman ES, et al. Diminished lipoxin biosynthesis in severe asthma. Am J Respir Crit Care Med 2005; 172: 824-830.
22 Vachier I, Bonnans C, Chavis C, et al. Severe asthma is associated with a loss of $1 \times 4$, an endogenous antiinflammatory compound. J Allergy Clin Immunol 2005; 115: 55-60.

23 Planaguma A, Kazani S, Marigowda G, et al. Airway lipoxin A4 generation and lipoxin A4 receptor expression are decreased in severe asthma. Am J Respir Crit Care Med 2008; 178: 574-582.

24 Comhair SA, Ricci KS, Arroliga M, et al. Correlation of systemic superoxide dismutase deficiency to airflow obstruction in asthma. Am J Respir Crit Care Med 2005; 172: 306-213.

25 Huynh ML, Malcolm KC, Kotaru C, et al. Defective apoptotic cell phagocytosis attenuates prostaglandin E2 and 15-hydroxyeicosatetraenoic acid in severe asthma alveolar macrophages. Am J Respir Crit Care Med 2005; 172: 972-979.

26 Vignola AM, Chiappara G, Siena L, et al. Proliferation and activation of bronchial epithelial cells in corticosteroiddependent asthma. J Allergy Clin Immunol 2001; 108: 738-746.

27 Balzar S, Chu HW, Silkoff P, et al. Increased TGF- $\beta 2$ in severe asthma with eosinophilia. J Allergy Clin Immunol 2005; 115: 110-117.

28 Holgate ST, Holloway J, Wilson S, et al. Epithelialmesenchymal communication in the pathogenesis of chronic asthma. Proc Am Thorac Soc 2004; 1: 93-98.

29 Joos GF, Germonpre PR, Pauwels RA. Role of tachykinins in asthma. Allergy 2000; 55: 321-337.

30 Busse WW, Banks-Schlegel S, Wenzel SE. Pathophysiology of severe asthma. J Allergy Clin Immunol 2000; 106: 1033-1042.

31 Carroll N, Carello S, Cooke C, et al. Airway structure and inflammatory cells in fatal attacks of asthma. Eur Respir J 1996; 9: 709-715.

32 Mauad T, Silva LF, Santos MA, et al. Abnormal alveolar attachments with decreased elastic fiber content in distal lung in fatal asthma. Am J Respir Crit Care Med 2004; 170: 857-862.

33 Busacker A, Newell JD Jr, Keefe T, et al. A multivariate analysis of risk factors for the air-trapping asthmatic phenotype as measured by quantitative ct analysis. Chest 2009; 135: 48-56.

34 Barnes PJ. Corticosteroid resistance in airway disease. Proc Am Thorac Soc 2004; 1: 264-268.

35 ten Brinke A, Zwinderman AH, Sterk PJ, et al. "Refractory" eosinophilic airway inflammation in severe asthma: effect of parenteral corticosteroids. Am J Respir Crit Care Med 2004; 170: 601-605.

36 Bonnans C, Chanez P, Meziane H, et al. Glucocorticoid receptor-binding characteristics in severe asthma. Eur Respir J 2003; 21: 985-988.

37 Goleva E, Hauk PJ, Hall CF, et al. Corticosteroid-resistant asthma is associated with classical antimicrobial activation of airway macrophages. J Allergy Clin Immunol 2008; 122: 550-559.

38 Bhavsar P, Hew M, Khorasani N, et al. Relative corticosteroid insensitivity of alveolar macrophages in severe asthma compared with non-severe asthma. Thorax 2008; 63: 784-790.

39 Godard P, Chanez P, Siraudin L, et al. Costs of asthma are correlated with severity: a 1-yr prospective study. Eur Respir J 2002; 19: 61-67. 
40 Sullivan SD, Rasouliyan L, Russo PA, et al. Extent, patterns, and burden of uncontrolled disease in severe or difficultto-treat asthma. Allergy 2007; 62: 126-133.

41 Gaga M, Papageorgiou N, Yiourgioti G, et al. Risk factors and characteristics associated with severe and difficult to treat asthma phenotype: an analysis of the ENFUMOSA group of patients based on the ECRHS questionnaire. Clin Exp Allergy 2005; 35: 954-959.

42 ten Brinke A, Sterk PJ, Masclee AA, et al. Risk factors of frequent exacerbations in difficult-to-treat asthma. Eur Respir J 2005; 26: 812-818.

43 Miller MK, Lee JH, Blanc PD, et al. TENOR risk score predicts healthcare in adults with severe or difficult-totreat asthma. Eur Respir J 2006; 28: 1145-1155.

44 Haselkorn T, Lee JH, Mink DR, et al. Racial disparities in asthma-related health outcomes in severe or difficult-to-treat asthma. Ann Allergy Asthma Immunol 2008; 101: 256-263.

45 Sullivan SD, Wenzel SE, Bresnahan BW, et al. Association of control and risk of severe asthma-related events in severe or difficult-to-treat asthma patients. Allergy 2007; 62: 655-660.

46 Haselkorn T, Borish L, Miller DP, et al. High prevalence of skin test positivity in severe or difficult-to-treat asthma. J Asthma 2006; 43: 745-752.

47 Borish L, Chipps B, Deniz Y, et al. Total serum IgE levels in a large cohort of patients with severe or difficult-to-treat asthma. Ann Allergy Asthma Immunol 2005; 95: 247-253.

48 Chipps BE, Szefler SJ, Simons FE, et al. Demographic and clinical characteristics of children and adolescents with severe or difficult-to-treat asthma. J Allergy Clin Immunol 2007; 119: 1156-1163.

49 Lee JH, Haselkorn T, Borish L, et al. Risk factors associated with persistent airflow limitation in severe or difficult-totreat asthma: insights from the TENOR study. Chest 2007; 132: 1882-1889.

50 Mascia K, Haselkorn T, Deniz YM, et al. Aspirin sensitivity and severity of asthma: evidence for irreversible airway obstruction in patients with severe or difficult-to-treat asthma. J Allergy Clin Immunol 2005; 116: 970-975.

51 National Heart, Lung, and Blood Institute. National Asthma Education and Prevention Program. Expert Panel Report 3: Guidelines for the Diagnosis and Management of Asthma. Full Report 2007. www.nhlbi.nih.gov/guidelines/asthma/asthgdln.pdf Last accessed: March 2009. Last updated: July 2007.

52 Thomson NC, Chaudhuri R. Asthma in smokers: challenges and opportunities. Curr Opin Pulm Med 2009; 15: 39-45.

53 Campbell JD, Blough DK, Sullivan SD. Comparison of guideline-based control definitions and associations with outcomes in severe or difficult-to-treat asthma. Ann Allergy Asthma Immunol 2008; 101: 474-481.

54 Haldar P, Pavord ID, Shaw DE, et al. Cluster analysis and clinical asthma phenotypes. Am J Respir Crit Care Med 2008; 178: 218-224.

55 ten Brinke A, van Dissel JT, Sterk PJ, et al. Persistent airflow limitation in adult-onset nonatopic asthma is associated with serologic evidence of Chlamydia pneumoniae infection. J Allergy Clin Immunol 2001; 107: 449-454.

56 Szefler SJ, Martin RJ, King TS, et al. Significant variability in response to inhaled corticosteroids for persistent asthma. J Allergy Clin Immunol 2002; 109: 410-418.
57 Bateman ED, Cheung D, Lapa e Silva J, et al. Randomized comparison of ciclesonide 160 and 640 microg/day in severe asthma. Pulm Pharmacol Ther 2008; 21: 489-498.

58 Reddel HK, Jenkins CR, Marks GB, et al. Optimal asthma control, starting with high doses of inhaled budesonide. Eur Respir J 2000; 16: 226-235.

59 Reddel HK. Goals of asthma treatment: how high should we go? Eur Respir J 2004; 24: 715-717.

60 Global Initiative for Asthma. Global Strategy for Asthma Management and Prevention, 2007 update. www.ginasthma. com/Guidelineitem.asp?1152\&l251\&intId Last accessed: March 2009. Last updated: 2008.

61 Campbell JD, Borish L, Haselkorn T, et al. The response to combination therapy treatment regimens in severe/ difficult-to-treat asthma. Eur Respir J 2008; 32: 1237-1242.

62 Cates CJ, Lasserson TJ. Combination formoterol and inhaled steroid versus $\beta_{2}$-agonist as relief medication for chronic asthma in adults and children. Cochrane Database Syst Rev 2009; 1: CD007085.

63 Samitas K, Chorianopoulos D, Vittorakis S, et al. Exhaled cysteinyl-leukotrienes and 8-isoprostane in patients with asthma and their relation to clinical severity. Respir Med 2008; [Epub ahead of print PMID: 19110408].

64 Strunk RC, Bacharier LB, Phillips BR, et al. Azithromycin or montelukast as inhaled corticosteroid-sparing agents in moderate-to-severe childhood asthma study. J Allergy Clin Immunol 2008; 122: 1138-1144.

65 Tonelli M, Zingoni M, Bacci E, et al. Short-term effect of the addition of leukotriene receptor antagonists to the current therapy in severe asthmatics. Pulm Pharmacol Ther 2003; 16: 237-240.

66 American Lung Association Asthma Clinical Research Centers. Clinical trial of low-dose theophylline and montelukast in patients with poorly controlled asthma. Am J Respir Crit Care Med 2007; 175: 235-242.

$67 \mathrm{Kim}$ SH, Ye YM, Hur GY, et al. CysLTR1 promoter polymorphism and requirement for leukotriene receptor antagonist in aspirin-intolerant asthma patients. Pharmacogenomics 2007; 8: 1143-1150.

68 Lazarus SC, Chinchilli VM, Rollings NJ, et al. Smoking affects response to inhaled corticosteroids or leukotriene receptor antagonists in asthma. Am J Respir Crit Care Med 2007; 175: 783-790.

69 Lee DK, Haggart K, Robb FM, et al. Montelukast protects against nasal lysine-aspirin challenge in patients with aspirin-induced asthma. Eur Respir J 2004; 24: 226230.

70 Peters-Golden M, Swern A, Bird SS, et al. Influence of body mass index on the response to asthma controller agents. Eur Respir J 2006; 27: 495-503.

71 Westby M, Benson M, Gibson P. Anticholinergic agents for chronic asthma in adults. Cochrane Database Syst Rev 2004; 3: CD003269.

72 Iwamoto H, Yokoyama A, Shiota N, et al. Tiotropium bromide is effective for severe asthma with noneosinophilic phenotype. Eur Respir J 2008; 31: 1379-1380.

73 Park HW, Yang MS, Park CS, et al. Additive role of tiotropium in severe asthmatics and Arg16Gly in ADRB2 as a potential marker to predict response. Allergy 2009; [Epub ahead of print PMID: 19183167]. 
74 Walker S, Monteil M, Phelan K, et al. Anti-IgE for chronic asthma in adults and children. Cochrane Database Syst Rev 2006; 2: CD003559.

75 Slavin RG, Ferioli C, Tannenbaum SJ, et al. Asthma symptom re-emergence after omalizumab withdrawal correlates well with increasing and decreasing pharmacokinetic concentrations. J Allergy Clin Immunol 2009; 123: 107-113.

76 Humbert M, Boulet LP, Niven RM, et al. Omalizumab therapy: patients who achieve greatest benefit for their asthma experience greatest benefit for rhinitis. Allergy 2009; 64: 81-84.

77 Berry MA, Hargadon B, Shelley M, et al. Evidence of a role of tumor necrosis factor alpha in refractory asthma. $N$ Engl J Med 2006; 354: 697-708.

78 Wenzel SE, Barnes PJ, Bleecker ER, et al. A randomized, double-blind, placebo-controlled study of TNF $\alpha$ blockade in severe persistent asthma. Am J Respir Crit Care Med 2009; [Epub ahead of print PMID: 19136369].

79 Kostadima E, Tsiodras S, Alexopoulos EI, et al. Clarithromycin reduces the severity of bronchial hyperresponsiveness in patients with asthma. Eur Respir J 2004; 23: 714-717.
80 Simpson JL, Powell H, Boyle MJ, et al. Clarithromycin targets neutrophilic airway inflammation in refractory asthma. Am J Respir Crit Care Med 2008; 177: 148-155.

81 Flood-Page P, Menzies-Gow A, Phipps S, et al. Anti-IL-5 treatment reduces deposition of ecm proteins in the bronchial subepithelial basement membrane of mild atopic asthmatics. J Clin Invest 2003; 112: 1029-1036.

82 Haldar P, Brightling CE, Hargadon B, et al. Mepolizumab and exacerbations of refractory eosinophilic asthma. $N$ Engl J Med 2009; 360: 973-984.

83 Nair P, Pizzichini MM, Kjarsgaard M, et al. Mepolizumab for prednisone-dependent asthma with sputum eosinophils. N Engl J Med 2009; 360: 985-993.

84 Busse WW, Israel E, Nelson HS, et al. Daclizumab improves asthma control in patients with moderate to severe persistent asthma: a randomized, controlled trial. Am J Respir Crit Care Med 2008; 178: 1002-1008.

85 Cox G, Thomson NC, Rubin AS, et al. Asthma control during the year after bronchial thermoplasty. N Engl J Med 2007; 356: 1327-1337. 